\title{
Morphological Characterization of Elite Kabuli Chickpea Lines
}

\author{
Sarla Kumawat ${ }^{*}$, Anita Babbar ${ }^{1}$, Ravindra Singh Solanki ${ }^{2}$, \\ Manoranjan Biswal ${ }^{1}$ and Prabha Banjarey ${ }^{1}$
}

\author{
${ }^{1}$ Department of Plant Breeding and Genetics, Jawaharlal Nehru Krishi Vishwa Vidyalaya, \\ Jabalpur (MP), 482004, India \\ ${ }^{2}$ ATARI Zone-IX, Jabalpur (MP), 482004, India \\ *Corresponding author
}

\begin{tabular}{l} 
K e y w o r d s \\
$\begin{array}{l}\text { Morphological } \\
\text { characterization, } \\
\text { kabuli } \text { Chickpea, } \\
\text { DUS test }\end{array}$ \\
Article Info \\
$\begin{array}{l}\text { Accepted: } \\
\text { 12 August } 2020 \\
\text { Available Online: } \\
\text { 10 September } 2020\end{array}$ \\
\hline
\end{tabular}

\section{A B S T R A C T}

Characterization of 89 kabuli chickpea lines were received from different sources (SAU's, ICRISAT and ICARDA) based on seventeen agro-morphological traits recorded in two rabi season 2018-19 and 2019-20. Results showed that 28 lines were semi-spreading, 44 semi-erect while 17 lines were erect type. Further, seventy six lines were recorded medium stature, 8 short, whereas 5 lines tall. Lines FLIP12-278C, FLIP122-161C, JGK-2018-5, ICCV1811909 and ICCV181305 had semi erect to erect type with tall stature would be suitable for mechanical harvesting. All lines characterized by white colour flower with no stripes on standard and had one flower per peduncle, no anthocyanin pigmentation and pinnate type of leaf pattern. Foliage colour showed wide variation, 6 lines had dark green, 55 lines had light green and 28 lines had medium green. Results exhibited that 37 lines were recorded as early flowering, better suited to grow under late sown conditions, whereas 50 lines medium and 2 lines were recorded late flowering. All the kabuli lines recognized as owl's head shape seed having beige colour seed coat with smooth seed surface. Among 89 lines ICCV181313 was recorded small seeded and 40 lines were medium seeded whereas seven kabuli chickpea lines were recorded extra large seeded (JGK-2018-1,2,3,4, RVSVT-K-105,110 and ICCV181307) and 33 large seeded would be screen out as export purpose and also used in hybridization programme. Therefore, characterization facilitates to develop distinct profile of these lines and helped in identification and evaluation of elite kabuli chickpea lines.

\section{Introduction}

Chickpea provides high quality protein for human and animal consumption as well as offers economic benefits to farmers because of the high market value for chickpea grains and not only meets its own nitrogen requirement but also leaves residual nitrogen for succeeding crop, improves physical and chemical properties of the soil, and decreases pests, diseases and weeds of rainy season (kharif) crops Kabuli chickpea fetches higher price than desi varieties and thus could work as a catalyst in bringing additional area under irrigated condition of the country and also improving livelihood of the pulse growers It. 
It is one of the oldest and widely cultivated pulse crops over 50 countries of the world.

Traditionally, characterization of morphological traits has been used as a basis for classification, visual identification, differentiation and cataloguing of the germplasm. It could unveil their phylogeny, which considerably beneficial to a plant breeder in utilizing these germplasm in frontier area of research programme of chickpea. Morphological characterization studies are done by using morphological markers that are highly heritable traits. They are inexpensive, simple and rapid to score. The measurement of the descriptor is used to assess diversity, but the environmental effect on these traits renders this measure relatively insensitive, particularly where differences are small. Therefore, morphological markers need to be supported with more sensitive markers especially when measuring diversity between and within populations of a single species (Williams et al., 1990).

Plant morphological characters have been recognized as the universally undisputed descriptors for DUS testing and varietal characterization of crop varieties (Joshi et al., 2018). Thus, any morphological character that is associated and makes a significant contribution to higher seed yield would be useful in the improvement of yield. According to aforesaid facts, this investigation was carried out to characterize 89 elite kabuli lines on the basis of qualitative DUS descriptor which facilitates to identify distinguish line, further it would be used in chickpea improvement programme.

\section{Materials and Methods}

The study was conducted on the site of seed breeding farm, Jawaharlal Nehru Krishi Vishwa Vidyalaya, Jabalpur during two rabi seasons of 2018-19 and 2019-20. The experimental material comprised of 89 elite lines of kabuli chickpea included 2 checks. Elite lines of kabuli chickpea were obtained from ICRISAT (Pattancheru), ICARDA (Morocco) and JNKVV (Jabalpur). All lines were evaluated in three replications using Randomized Complete Block Design (RCBD) with each entry in two rows of $4.0 \mathrm{~m}$ length in each replication. Inter and intra-row space was $45 \mathrm{x} 10 \mathrm{~cm}$. The recommended agronomical and plant protection practices were followed for the successful raising of the crop. Observations were recorded on 18 qualitative traits including morphological and seed traits based on the DUS guide line of chickpea for each character in each replication at different crop growth stages. Qualitative traits along with its descriptors and stage of observation have been depicted in Table 1 .

\section{Results and Discussion}

Crop improvement in chickpea is hampered due to the presence of narrow genetic base which need to be broadened so as to realize the genetic potential of these lines. Hence, assessment of genetic diversity is a prerequisite for formulating crop improvement strategies in any crop. Since, the assessment of the genetic diversity and characterization of primary genetic resource specimens is one of the most important conditions for the proper and rational use of working collections in future breeding programmes. Therefore, agro-morphological traits of different lines studied and showed that although some of the lines have common qualitative features rather than one or few characters, they can be differentiated from each other on the basis of their mono-morphic traits. The objective of this investigation was to characterize the kabuli chickpea lines for seventeen qualitative traits on the basis of DUS guideline and prepared their distinct profile to discriminate the different lines. 
No variation was found among the elite lines for Leaf pattern and all they had pinnate type of leaf pattern. Plant growth habit is a distinguishing feature in plant characterization of chickpea. Large variation was observed in growth habit 28 lines were semi spreading, 44lines, semi-erect, while 17 lines were erect type. Further, Seventy six lines among 89 recorded medium stature, 8 lines short, whereas 5 lines were tall. Lines viz., FLIP 12-278C, FLIP 122-161C, JGK2018-5, ICCV 1811909 and ICCV 181305 had semi erect to erect type with tall stature would be suitable for mechanical harvesting. Results indicated that there was wide variation showed in foliage color, 55 lines showed light green, 28 lines observed medium green, while 6 lines showed dark green. It is a visual trait easily observable in vegetative stage of plant. In order to size of leaflets, the variation was observed in the lines which were categorized into three main groups viz; small, medium and large, 11 lines observed small size leaflets $(10.0 \mathrm{~mm}), 55$ observed medium $(10.0-15.0 \mathrm{~mm})$, while the remaining 23 were large $(>15.0 \mathrm{~mm})$ leaflets size. Color of flower is one of the most important diagnostic visual easily observable traits. It is widely used as a marker gene in genetic studies and breeding work.

All indegineous and exotic kabuli chickpea lines were characterized by white colour flower with no stripes on standard and had one flower per peduncle. No anthocyanin pigmentation and dark coloration on stem, whole plant and pods and all lines had pinnate type of leaf pattern. The peduncle length is a peculiar trait, can be classified in to three categories 7 lines exhibited short peduncle, while in 32 lines noted medium peduncle length and the remaining 50 lines showed long peduncle (Fig. 1-3; Table 2).

Table.1 List of Morphological Traits with Descriptors

\begin{tabular}{|c|c|c|c|}
\hline $\begin{array}{l}\text { S.No. } \\
\text { n }\end{array}$ & Characteristics & Descriptors & Stage of observation \\
\hline 1 & Stem: Anthocynin coloration & Absent, Present & Before flowering \\
\hline 2 & Plant: Growth habit & $\begin{array}{l}\text { Erect, Semi-erect, Semi Spreading, } \\
\text { Spreading }\end{array}$ & $50 \%$ flowering \\
\hline 3 & Color of foliage & $\begin{array}{l}\text { Light green, Medium green } \\
\text { Dark green, Greenish purple }\end{array}$ & $50 \%$ flowering \\
\hline 4 & Leaflet: Size & Small, Medium, Large & $50 \%$ flowering \\
\hline 5 & Leaf: Pattern & Simple, Compound, Pinnate & $50 \%$ flowering \\
\hline 6 & Flower: Color & White, Pink, Blue, Purple & $50 \%$ flowering \\
\hline 7 & Peduncle: Length(mm) & Short, Medium, Long & Pod development \\
\hline 8 & Seed: Color & $\begin{array}{l}\text { Beige (Kabuli), Creamy beige, Green, } \\
\text { Yellow, Orange, Brown, Dark brown, Grey, } \\
\text { Black }\end{array}$ & 30 days after harvest \\
\hline 9 & Seed: Size & $\begin{array}{l}\text { Very small, Small, Medium, Large, Very } \\
\text { large }\end{array}$ & 30 days after harvest \\
\hline 10 & Seed: Shape & Pea-shaped, Owl's head, Angular & 30 days after harvest \\
\hline 11 & Seed: Testa texture & Rough, Smooth, Tuberculated & 30 days after harvest \\
\hline 12 & Seed: Ribbing & Absent, Present & 30 days after harvest \\
\hline
\end{tabular}


Table.2 Characterization of kabuli chickpea lines on the basis of distinguishable morphological traits

\begin{tabular}{|c|c|c|c|c|}
\hline $\begin{array}{l}\text { S. } \\
\text { No. }\end{array}$ & Traits & Expressions & $\begin{array}{c}\text { No of genotypes } \\
\text { belonging to each } \\
\text { class }\end{array}$ & $\begin{array}{c}\text { Percentage } \\
\text { contributions } \\
\%\end{array}$ \\
\hline \multirow[t]{3}{*}{1.} & \multirow{3}{*}{ Growth habit } & Erect $\left(0-15^{0}\right.$ from vertical $)$ & 17 & 19.1 \\
\hline & & Semi-erect (16-250 from vertical) & 44 & 49.4 \\
\hline & & $\begin{array}{l}\text { Semi-spreading }\left(26-60^{\circ} \text { from }\right. \\
\text { vertical) }\end{array}$ & 28 & 31.4 \\
\hline \multirow[t]{3}{*}{2.} & \multirow[t]{3}{*}{ Size of leaflets } & Small (<10mm long- 4mm wide) & 11 & 12.3 \\
\hline & & $\begin{array}{l}\text { Medium (10-15mm long, } 412 \mathrm{~mm} \\
\text { wide }\end{array}$ & 55 & 61.8 \\
\hline & & Large $(>15 \mathrm{~mm}$ long, $>12 \mathrm{~mm}$ wide) & 23 & 26 \\
\hline \multirow[t]{3}{*}{3.} & \multirow{3}{*}{$\begin{array}{l}\text { Time of } 50 \% \\
\text { flowering }\end{array}$} & Early (40-60 days) & 37 & 41.5 \\
\hline & & Medium (61-80 days) & 50 & 56.1 \\
\hline & & Late ( $>80$ days) & 2 & 2.2 \\
\hline \multirow[t]{3}{*}{4.} & \multirow{3}{*}{$\begin{array}{l}\text { Plant height } \\
\text { (cm) }\end{array}$} & Short $(<45 \mathrm{~cm})$ & 8 & 8.9 \\
\hline & & Medium $(45-65 \mathrm{~cm})$ & 76 & 85.3 \\
\hline & & Tall $(>65 \mathrm{~cm})$ & 5 & 5.6 \\
\hline 5. & $\begin{array}{l}\text { Flower stripes on } \\
\text { standard }\end{array}$ & Absent & 89 & 100 \\
\hline 6. & Flower color & White & 89 & 100 \\
\hline 18. & $\begin{array}{l}\text { Flower number per } \\
\text { peduncle }\end{array}$ & One & 89 & 100 \\
\hline \multirow[t]{3}{*}{7.} & \multirow[t]{3}{*}{ Foliage colour } & Dark green & 6 & 6.7 \\
\hline & & Light green & 55 & 61.8 \\
\hline & & Medium green & 28 & 31.5 \\
\hline 8. & Leaf pattern & Pinnate & 89 & 100 \\
\hline 9. & $\begin{array}{l}\text { Stem anthocyanin } \\
\text { coloration }\end{array}$ & Absent & 89 & 100 \\
\hline \multirow[t]{3}{*}{10.} & \multirow{3}{*}{$\begin{array}{l}\text { Peduncle length } \\
(\mathrm{mm})\end{array}$} & Short $(<5 \mathrm{~mm})$ & 7 & 7.9 \\
\hline & & Medium (5-10mm) & 32 & 35.9 \\
\hline & & Long $(>10 \mathrm{~mm})$ & 50 & 56.2 \\
\hline 11. & Seed colour & Beige & 89 & 100 \\
\hline \multirow[t]{4}{*}{12.} & \multirow[t]{4}{*}{ Seed size } & small & 1 & 1.1 \\
\hline & & Medium & 48 & 53.9 \\
\hline & & Large & 33 & 37.1 \\
\hline & & Extra large & 7 & 7.8 \\
\hline 13. & Seed shape & Owl head & 89 & 100 \\
\hline 14. & Seed surface/ texture & Smooth & 89 & 100 \\
\hline 15. & Seed ribbing & Absent & 89 & 100 \\
\hline 16. & Seed type & kabuli & 89 & 100 \\
\hline 17. & $\begin{array}{l}\text { Shattering resistance } \\
(\%)\end{array}$ & Absent & 89 & 100 \\
\hline
\end{tabular}


Fig.1 Plant growth habit
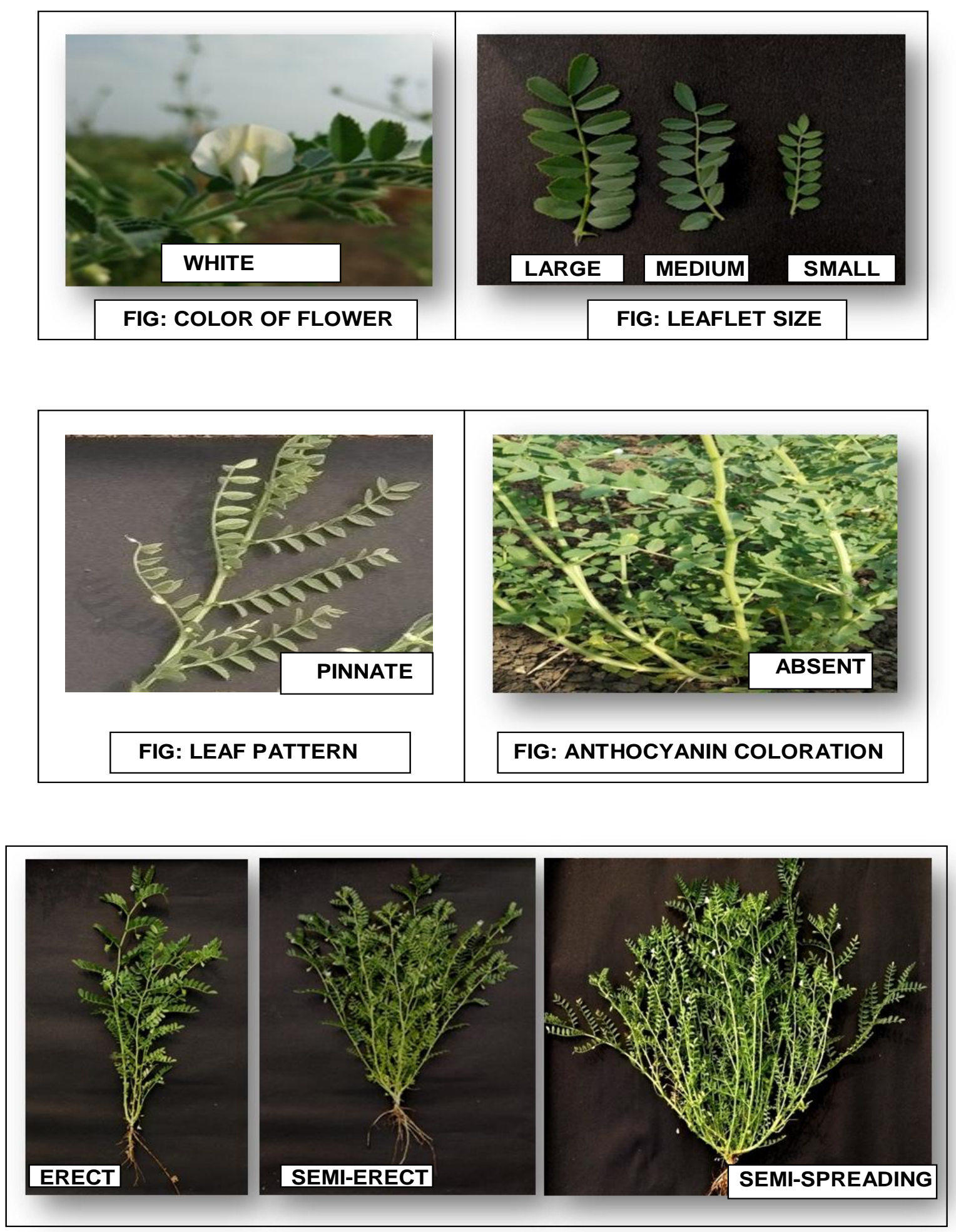
Fig.2 Seed size (weight of 100 seeds at $10 \%$ moisture

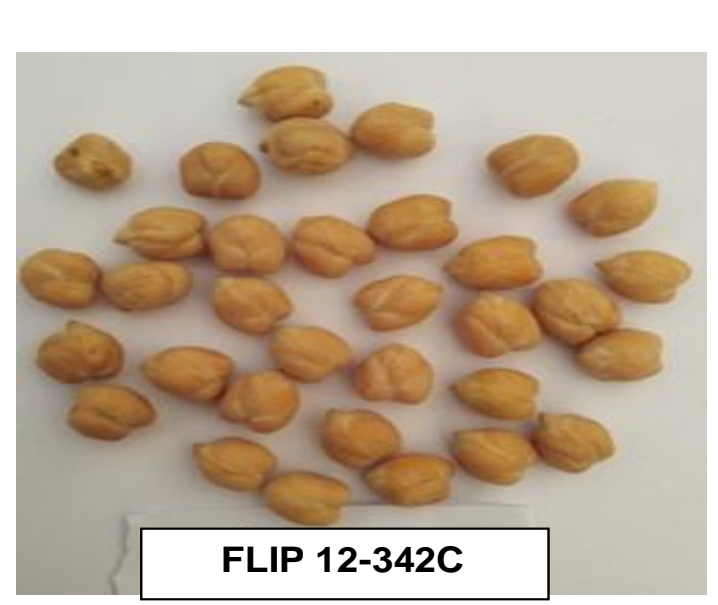

FIG: SEED SHAPE: OWL'S HEAD

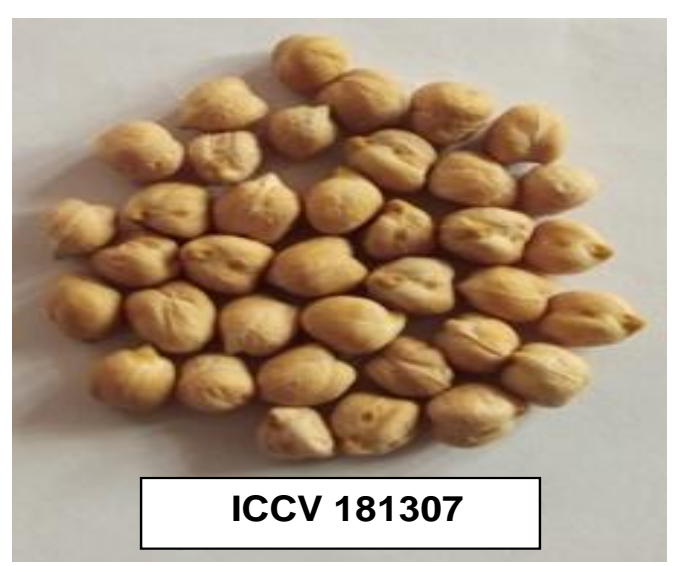

FIG: SEED RIBBING: ABSENT
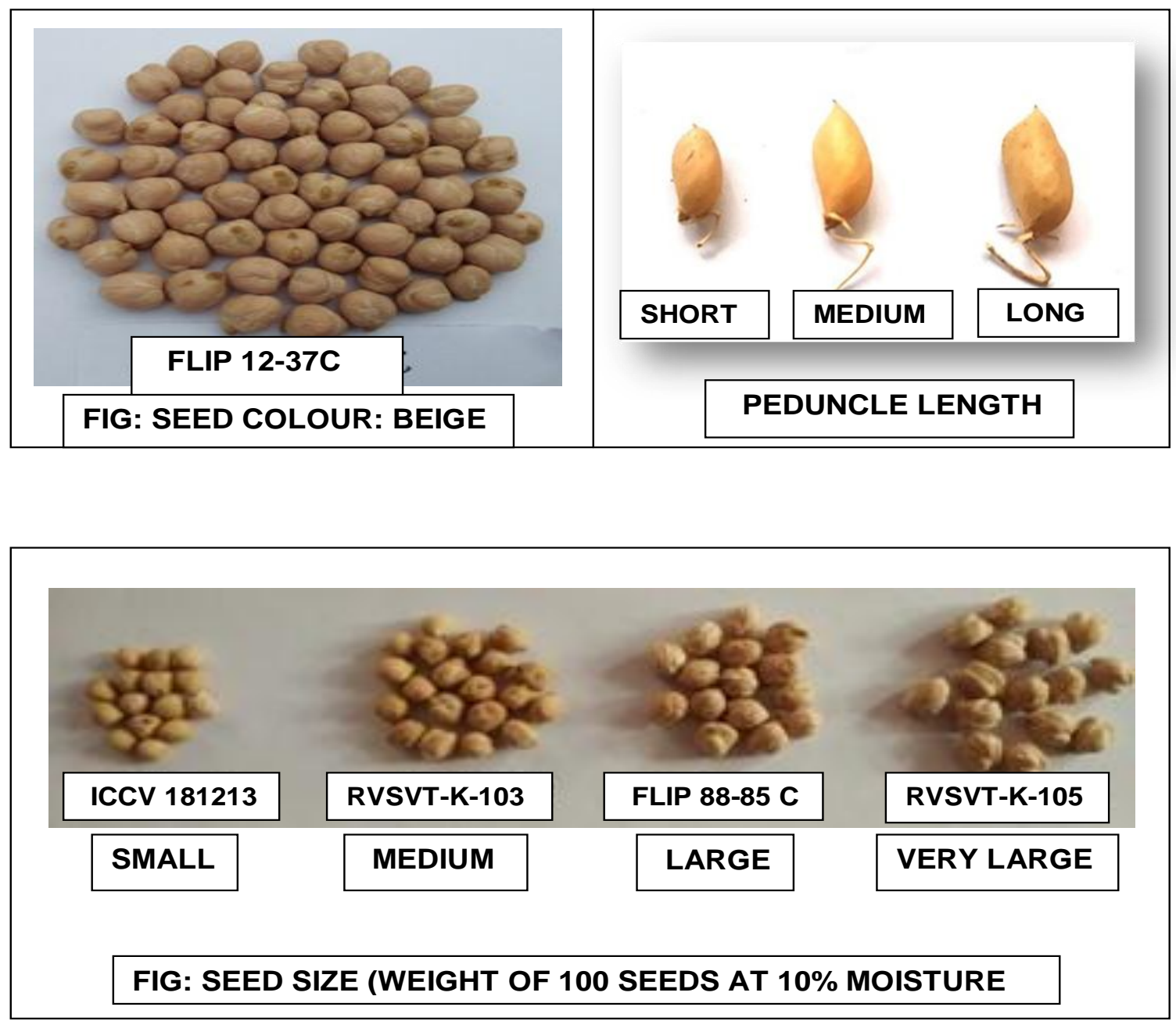
Fig.3 Morphological Characters
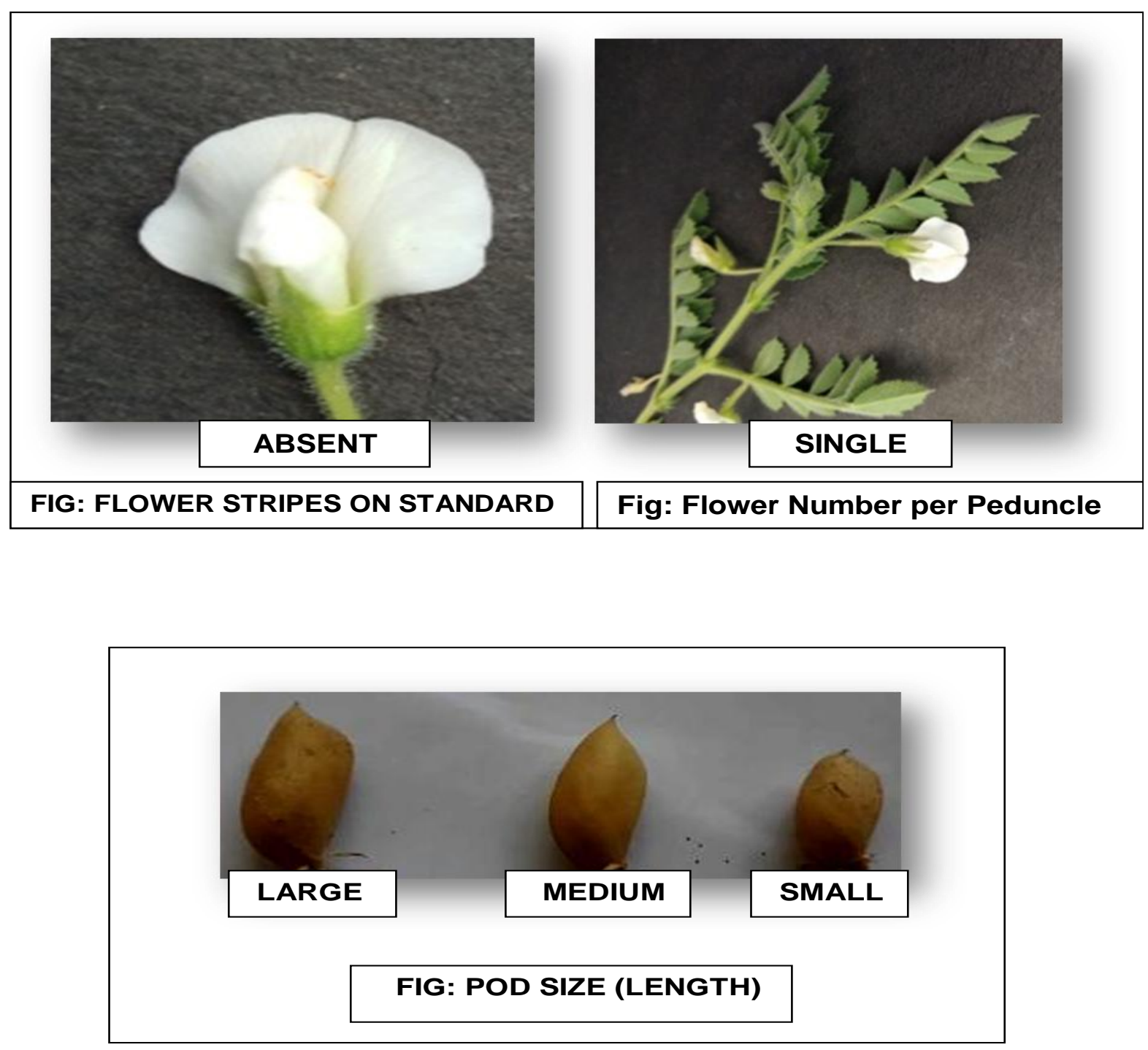

All the kabuli lines recognized as owl's head shape seed, having beige colour seed coat with smooth seed surface. For kabuli chickpea, seed size is a most preferable traits to the consumers because large and extra large seeded kabuli chickpea fetches 2-3 times higher price than desi varieties and thus it could work as a catalyst in bringing additional area and improving livelihood of the pulse growers. Seed size traits showed mono-morphic as well as polymorphic.
Among 89 lines, a line ICCV 181313 recorded as small seed size (20-25g), showed mono morphic in nature, whereas 40 lines noted as medium seeded (26-35g), 33 elite lines as large seed seeded (36-45g) and seven kabuli chickpea lines recorded as extra large seeded (JGK- 2018-1,2,3,4, RVSVT-K-105, 110 and ICCV 181307). These large and extra large seeded lines would be screenout as export purpose and also used in chickpea hybridization programme. 
Understandings of various seed traits viz., seed color, size, shape and texture facilitate the identification for selection of desirable traits, designing new populations and transferring their desirable genes. These results supported by the research of (Solanki et al., 2019), and Loko et al., (2018), Bayahi et al.(2015), Shrivastava et al., (2012), Upadhyaya et al., (2008), Kaul et al., (2007). Morphological features of the lines have been a major component of varietal identification, distinctness, characterization and evaluation of best elite lines. Similar findings reported by earlier scientists (Gediya et al., 2018), Sangram Singh et al., (2018), Kosev and Vasileva (2018), Joshi et al., (2018), Bayahi and Rezgui (2015), saha (2017) and Zaccardelli et al., (2013).

It is not possible to identify advanced promising lines using any single parameter. A detailed morphological description of plants and seeds should therefore be assigned distinctive morphological profiles. Similar facts suggested by Janghel et al., (2020), Solanki et al., (2019), and Adem and Tesso (2019).

Differential behaviour in respect of growth, dry matter production potential and translocation of photosynthates from source to sink showed significant variation in yield which leads to distinguish lines from each other. Similar results noticed by Bodake et al., (2014) and Heidarvand et al., (2011).

Utilization of agro-morphological features in sequential fashion is useful and convenient to distinguish different genotypes. Similarly, genotypes identification based on distinguishable morphological characters were reported by (Sarao et al., 2009), Lalitha (2007), Upadhyaya et al., (2002), Yadav and Shrivastava (2002), Chowdhury et al., (2002) and Singh (2001) in chickpea, However systematic characterization leads to a more efficient use of material under consideration in chickpea improvement programme.

Results of investigation concluded that distinct morphological profile would be most practically valuable to a plant breeder while selecting genotypes in field and seed level. Morphological character those associated with higher seed yield or which makes a significant contribution to yield would be useful in the improvement of seed yield. Therefore, morphological characterization facilitates to develop distinct profile of these lines and helped in identification, characterization and evaluation of elite kabuli chickpea lines. Hence, systematic characterization leads to a more efficient use of material under consideration in chickpea improvement programme and these lines prefer to selection.

\section{Acknowledgment}

Author's gratitude and acknowledge to the ICRISAT, Pattancheru \& ICARDA, Morocco to provide research seed material and also who directly or indirectly help in my research.

\section{References}

Adem, A., and Tesso, B. 2019. Phenotypic Characterization and Assessment of Genetic Diversity for AgroMorphological Traits of Ethiopian Chickpea (Cicer arietinum L.) landraces. Black Sea Journal of Agriculture. 2(3):146-55.

Bayahi, K., and Rezgui, S. 2015. Agromorphological and genetic study of new improved lines and cultivars of chickpea. Journal of Plant Breeding and Genetics. 3(3):1-3.

Bodake, K.K., Wagh, R.S., and Deshmukh, D.V. 2014. Morpho-physiological characterization of chickpea (Cicer arietinum L.) genotypes. International 
Journal of Agricultural Sciences. 10(2):512-8.

Chowdhury, M.A., Bert, V.B., and Warkentin, T. 2002. Cultivar identification and genetic relationship among selected breeding lines and cultivars in chickpea (Cicer arietinum L.). Euphytica. 127(1-2): 317-325.

Gediya, L.N., Patel, D.A., Kumar, D. and Nayak, K.V. 2018. Characterization of chickpea genotypes based on morphological traits. Journal of Pharmacognosy and Phytochemistry. 7(4):3008-15.

Guidelines for the Conduct of Test for Distinctness, Uniformity and Stability on Chickpea (Cicer arietinum L.). 2018. http://www.plantauthority.gov.in/pdf/G Chick pea.pdf

Heidarvand, L., Reza, M.A., Mohammad, R.N., Yadollah, F., Behzad, S., and Khoshnood A. 2011. Physiological and morphological characteristics of chickpea accessions under low temperature stress. 58(1):126-32.

Janghel, D.K., Kumar, K., Sunil, R., and Chhabra, A.K. 2020. Genetic Diversity Analysis, Characterization and Evaluation of Elite Chickpea (Cicer arietinum L.) Genotypes. International Journal Current Microbiology Applied Science. 9(1):199-209.

Joshi, M. A., Aggarwal, D., and Sanyal, A. 2018. Cultivar identification and diversity analysis based on morphological descriptors and image analysis in chickpea (Cicer arietinum L.). Legume Research-An International Journal. 41(5):647-55.

Kaul, J., Kumar, S. and Gurha, S.N. 2007. Evaluation of exotic germplasm of kabuli chickpea. Indian Journal of Plant Genetic Resources. 20(2):1-3.

Kosev, V.I., and Vasileva, V.M. 2019. Morphological characterization of Grass pea (Lathyrus sativus L.) Varieties.
Journal of Agricultural Sciences-Sri Lanka. May 1; 14(2).

Lalitha, A. 2007. Varietal Characterization of chickpea (Cicer arietinum) varieties Journal Research Angrau. 44(3\&4).

Loko, L.E., Orobiyi, A., Adjatin, A., Akpo, J., Toffa, J., Djedatin, G., Dansi, A. 2018. Morphological characterization of common bean (Phaseolus vulgaris L.) landraces of Central region of Benin Republic.

Saha, S. 2017. Morphological Characterization and Genetic Analysis in Elite Lines of Chickpea (Cicer arietinum L.) (Doctoral dissertation, Jawaharlal Nehru Krishi Vishwa Vidyalaya Jabalpur).

Sangram, S., and Sasidharan, N. 2018. Assessment of genetic diversity in chickpea (Cicer arietanum L.) through morphological characterization. Plant Archives.;18(1):167-72.

Sarao, N.K., Joshi, M.A., Sharma, R.C., Sandhu, J.S. and Kumar, J. 2009. Characterization of chickpea based on morphological markers. Journal of Food Legumes 22(4): 251-253.

Shrivastava, A., Babbar, A., Shrivastava, S.P., and Shukla, S.S. Variability studies in some genotypes of chickpea (Cicer arietinum L.) under rice fallow. Journal of Food Legumes. 2012; 25(1):70-7

Singh, R. 2001. Characterization of chickpea cultivars by field and laboratory techniques (Doctoral dissertation, Chaudhary Charan Singh Haryana Agricultural University, Hisar,

Solanki, R.S., Biswal, M., Kumawat, S., and Babbar, A. 2019. Characterization of indigenous and exotic chickpea lines for qualitative traits. International Journal of Chemical Studies. 7(4): 1018-1023

Upadhyaya, H.D., Gowda, C.L., and Sastry, D.V. 2008. Plant genetic resources management: collection, characterization, conservation and 
utilization. Journal of SAT Agricultural Research. 6(1):16-17.

Upadhyaya, H.D., Ortiz, R., Bramel, P.J., and Singh, S. 2002. Phenotypic diversity for morphological and agronomic characteristics in chickpea core collection. Euphytica.; 123(3):333-42.

Williams, J.G., Kubelik, A.R., Livak, K.J., Rafalski, J.A., and Tingey, S.V. 1990. DNA polymorphisms amplified by arbitrary primers are useful as genetic markers. Nucleic acids research. 18(22):6531-5.
Yadav, R.D.S. and Shrivastava, J.P. 2002. DUS characteristics of chickpea varieties. Seed Tech News. 32(1):29-30. Zaccardelli, M., Sonnante, G., Lupo, F., Piergiovanni, A.R., Laghetti, G., Sparvoli, F., and Lioi, L. 2013. Characterization of Italian chickpea (Cicer arietinum L.) germplasm by multidisciplinary approach. Genetic resources and crop evolution. 60(3):865-877.

\section{How to cite this article:}

Sarla Kumawat, Anita Babbar, Ravindra Singh Solanki, Manoranjan Biswal and Prabha Banjarey. 2020. Morphological Characterization of Elite Kabuli Chickpea Lines. Int.J.Curr.Microbiol.App.Sci. 9(09): 1241-1250. doi: https://doi.org/10.20546/ijcmas.2020.909.152 